Reprod. Nutr. Develop. 1980, 20 (4 A), 939-948.

\title{
Influence of photoperiod on the time of parturition in the rat. II. Demonstration of a photoinducible phase and determination of some of its characteristics
}

par M. J. BOSC, Agnès NICOLLE

Station de Physiologie de la Reproduction, I.N.R.A. Nouzilly 37380 Monnaie, France.

\begin{abstract}
Summary. Parturition time has been chosen to investigate whether a photoinducible phase exists during the light-dark cycle in the rat. A 1-hr light stimulation was given during the dark phase at various times after the beginning of the principal photoperiod or conventional dawn. The rats kept under 8 hrs of light and 16 hrs of darkness from mating (day 1 of pregnancy) gave birth to most of their pups on the afternoon of day 22 of pregnancy when the light pulse was applied 9 to $18 \mathrm{hrs}$ or 22 to $23 \mathrm{hrs}$ after dawn. Parturition was delayed till day 23 when the light pulse was given 18 to 22 hrs after dawn. In the same manner, under $16 \mathrm{hrs}$ of light and 8 of darkness, most of the parturitions occurred on day 23 of pregnancy when a light pulse was given 22 hrs after dawn; they extended over two preferential periods - one on day 22 (about $50 \mathrm{p}$. 100) and the other on day 23 when the light pulse was given 16 to $17 \mathrm{hrs}$ or 18 to $19 \mathrm{hrs}$ after dawn. Thus, the stimulation of the photoinducible phase, found at the end of the dark period, resulted in retarded parturition. That delay was also observed when the light pulse was only given during the final days of pregnancy. Most parturitions occurred on day 22 of pregnancy under a short photoperiod to which 5 hrs of light were added during the dark phase at a time not coinciding with the photoinducible phase. This suggested that the effect of the principal light regime and the stimulation of the photoinducible phase could be dissociated.
\end{abstract}

\section{Introduction.}

The time of birth in the rat depends on the photoperiod (Plaut et al., 1970 ; Mitchell and Yochim, 1970 ; Bosc and Nicolle, 1980). However, it is not known how the daily illumination influences the physiological process leading to parturition. Among the theories proposed to explain photoperiodic responses, those based on an endogenous circadian rhythm of photosensitivity have provided an attractive model (Bunning, 1960 ; Pittendrich and Minis, 1964 ; Elliott, 1976), the main feature of which is that stimulation of the photodependent-biological process depends on the coincidence between light and the responsive part of the endogenous photosensitive rhythm, called the photoinducible phase. As recently outlined (Elliott, 1976), light has a dual role in this model (Pittendrigh and Minis, 1964). First, it acts as an entraining agent of the organism's many circadian rhythms and, secondly, it may or may not illuminate 
the photoinductible phase whose position depends on the light-dark cycle. This study was undertaken to demonstrate the existence of such a photoinductible phase in the rat and to determine some of its characteristics. The time of birth was then chosen to follow the effects of the light treatments.

\section{Material and methods.}

Two successive experiments were performed with rats of the Wistar strain. They were kept in rooms $(4.5 \times 2 \times 2.3 \times 2 \mathrm{~m})$ controlled for temperature and light. The standard regime was $14 \mathrm{hrs}$ of light and 10 of darkness (14L-10D). Details on the management of the rats have been given previously (Bosc and Nicolle, 1980).

The females were utilized serially. At 70-90 days of age, they were caged with males for 3-day periods. On the day of mating (spermatozoa detected in the vaginal smear), considered as day 1 of pregnancy, they were isolated in an individual box, and then assigned to an experimental group, two or three mating sessions being needed to complete each group. Each animal was permitted two pregnancies.

Experiment I. - The possibility that a photoinducible phase might exist was studied with two light regimes. We first used a short photoperiod, as described previously by Bosc and Nicolle (1980) that is, 8 hrs of light and 16 of darkness (8L-16D ; light on from 9 a. m. to 5 p. m.). Fourteen groups were studied with a mean number of 66 rats (range : 52 to 98). The details are given on figure 1 (Si groups, with i ranging from 10 through 23). Throughout pregnancy, each group received one additional hour of light at a fixed time in the dark period. The beginning of the main light period was considered as the subjective dawn (or time 0), and each group was characterized by the hour (indicated by i) at which the light pulse ended.

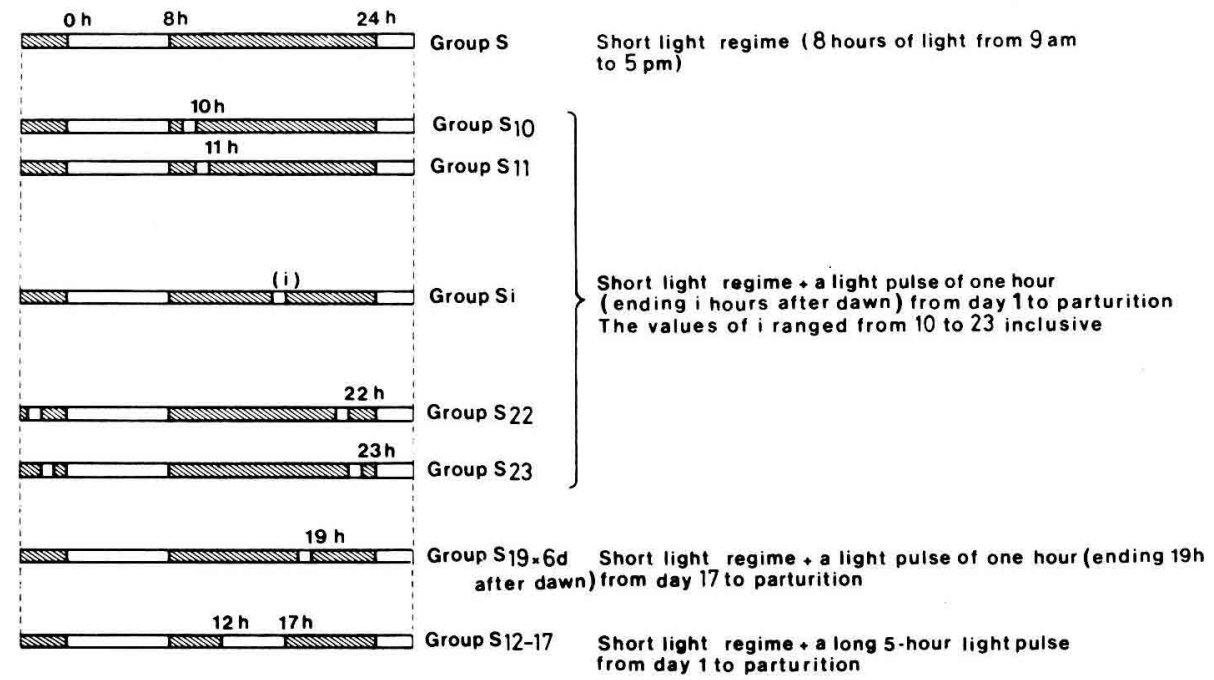

FIG. 1. - Procedure for determining a photoinducible phase under a short-light regime (8L-16D). Position of light pulses after « dawn 》 (Experiments I and II). 
We then carried out a similar test but used the standard light regime (14L-10D ; light on from 6 a. m. to 8 p. m.). Only three groups were given a light pulse of 1-hr ending at 17 (group C17 : 62 rats), 19 (group C19:50 rats) or 22 (group C22: 66 rats) hours after dawn.

Experiment II. - Following the results of the first experiment, two groups were established to determine some of the characteristics of the light pulse. The group used to study at which stage of pregnancy a light stimulation could affect the time of parturition (group S19-6d : 48 rats ; fig. 1) was submitted to the short-light regime and received a 1 -hr light pulse ending $19 \mathrm{hrs}$ after dawn from day 17 of pregnancy to parturition for a maximum of 6 days (d). The second group (group S12-17 : 32 rats; fig. 1) was subjected to the same basic light regime but received a long 5-hr light stimulation starting $12 \mathrm{hrs}$ and ending $17 \mathrm{hrs}$ after dawn. No light pulse effect was observed in the first experiment during this phase of the light-dark cycle.

Observations. - Observations were made as described previously by Bosc and Nicolle (1980), the onset of expulsion being taken as the time of delivery. Parturition frequencies were plotted at 2-hr intervals and analysed according to the non-parametric test of Kolmogoroff-Sirmnoff (Siegel, 1956). The results were compared with those obtained previously with the basic light regime (Bosc and Nicolle, 1980).

Total and live newborn rats were determined in each litter at the end of parturition and prolificies and stillbirth rates were compared statistically (Snedecor and Cochran, 1957).

\section{Results.}

\section{Experiment 1.}

We attempted to demonstrated a photosensitive phase under the short-light regime. The results of the $14 \mathrm{Si}$ groups have been summarized in figure 2 . When 1-hr of light stimulation was given at the beginning (groups S10, S11,..., S17) or at the very end of the dark period (group S23), the main period of parturition occurred in the second half of day 22 of pregnancy between 1 p. m. and 11 p. m., at least 60 p. 100 of the rats having delivered by the earlier time. In contrast, when the light pulse was given between 18 and $20 \mathrm{hrs}$ after « dawn » (groups S19 and S20, respectively), most of the animals delivered after 10 p. m. of day 22 and predominantly on the first-half of day 23. Groups S19 and S20 were both significantly different from all the others according to the Kolmogoroff-Sirmnoff test $(P<0.05$ in two cases ; $P<0.01$ in the others ; table 1$)$. Group S18 and groups S21 and S22 appeared to be intermediate between the two types of parturition distributions (table 1). The statistical analysis showed that group S14 was also different from the others (table 1) for in that group, most of the parturitions occurred within a very short time, probably accounting for the observed differences.

The stillbirth rates were affected by the light regime $(P<0.05)$, but the variation observed (range : 1.6 to 8.3 p. 100) was apparently unrelated to the light treatment. 


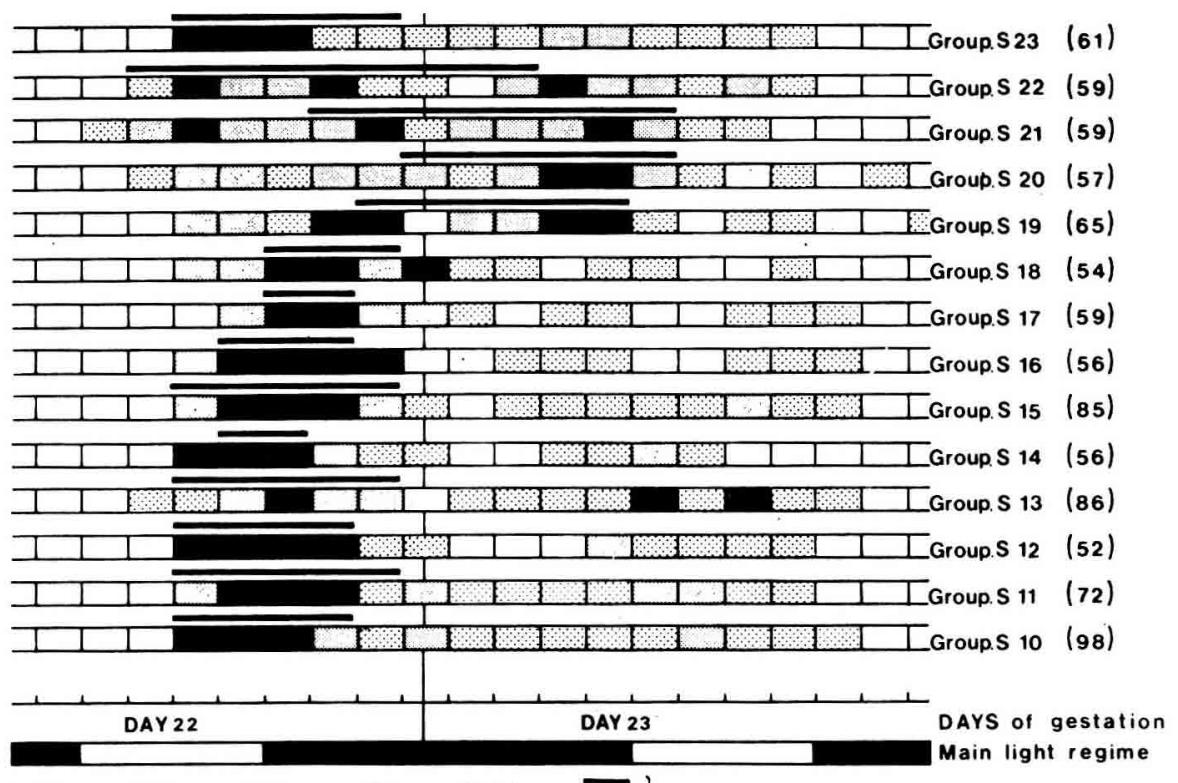

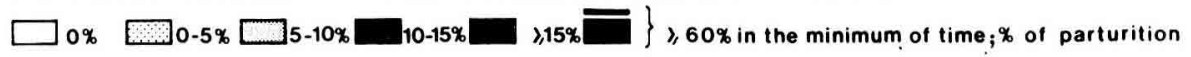
(...) number of rats

FIG. 2. - Parturition distributions in rats submitfed to a short-light regime (8L-16D) According to the time of a 1-hr light pulse during the night (Si groups) and throughout pregnancy.

TABLE 1

Comparisons between the parfurition distribution curves of groups $S 23$ to $\$ 10$ (Si groups)

\begin{tabular}{|c|c|c|c|c|c|c|c|c|c|c|c|c|c|}
\hline Groups & $\mathrm{S} 10$ & $s 11$ & $\mathrm{~S} 12$ & S13 & S14 & S15 & S16 & S17 & S18 & S19 & $\mathrm{S} 20$ & $S 21$ & $\mathrm{~S} 22$ \\
\hline
\end{tabular}

S10

S11

S12

S13

S14

S15

S16

S17

S18

S19

S20

S21

S22

S23

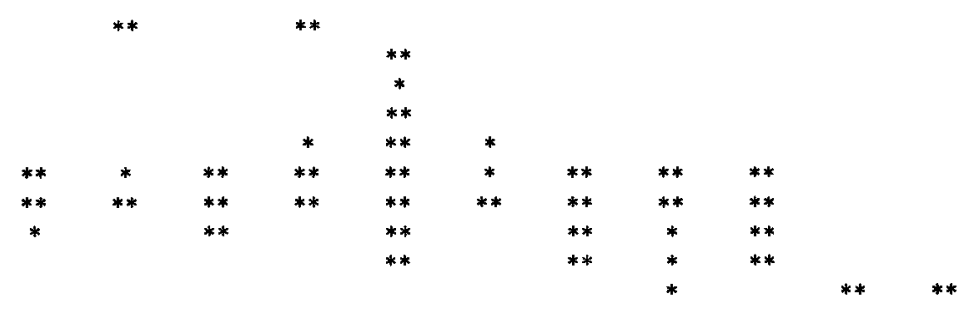

$2 \times 2$ comparisons from group $\$ 23$ to group $\$ 10$ according to the non-parametric test of Kolmogoroff-Smirnoff.

* $P<0.05$.

** $P<0.10$. 
The litter size of the 14 groups did not differ $(10.1+1.8 ;$ mean \pm residual variance ; range : 9.3 to $11.2 ; P>0.05$ ) but the mean litter size decreased slightly from day 22 of pregnancy to $10 \mathrm{a} . \mathrm{m}$. on day 23 ; thereafter, a more pronounced reduction was observed (fig. 3).

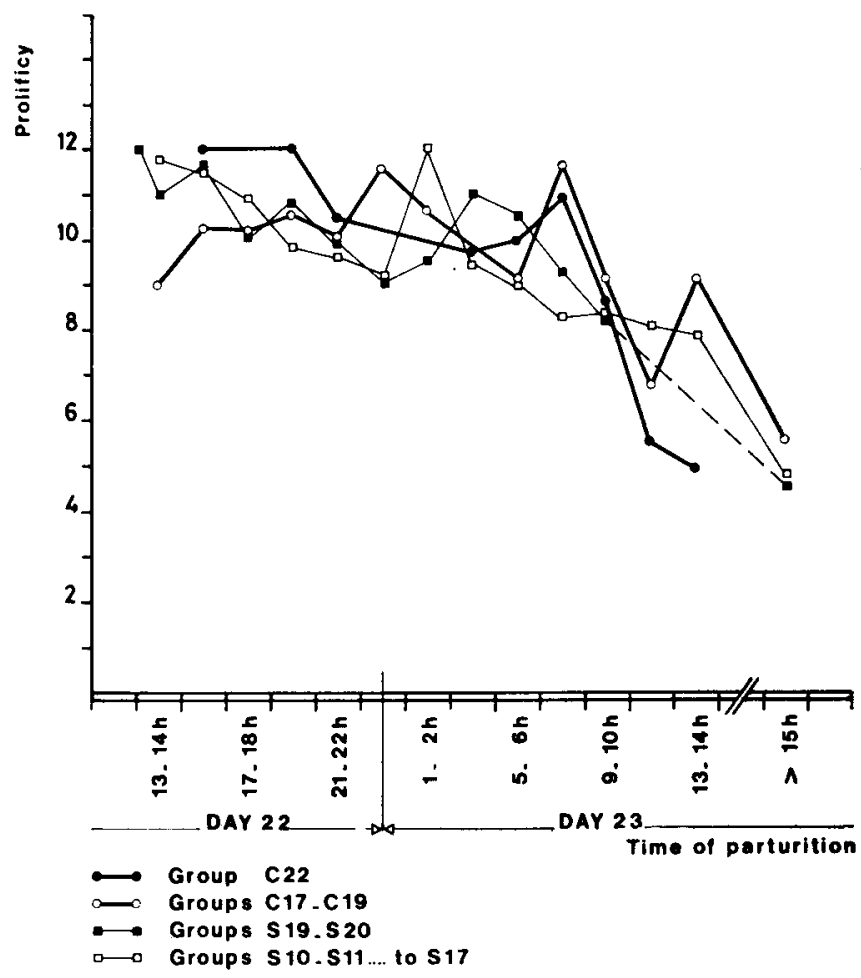

FIG. 3. - Mean litter size in the raf according to parturition time and to the light regime used during pregnancy. The number of rats per point varies according to time of birth and to treatment (range : 3 to 166$)$.

We also tried to show a photosensitive phase using the control light regime. The results are presented in figure 4 with the preceding observations obtained under the basic light regime. Two types of parturition distributions were found. With a light flash at the beginning of the dark phase or at midnight (groups C17 and C19), the deliveries occurred in two main periods : on day 22 of pregnancy and on day 23, as under the basic light regime. In comparison, a light stimulation at the end of the daily period of darkness (group C22) shifted the parturition time to day 23 of pregnancy. Group C22 was significantly different from groups C17 and C19 $(P<0.05)$. The stillbirth rates were affected by the treatment (range : 1.3 to 5.3 p. $100 ; P<0.01$ ) but the three groups had the same litter size (range : $9.5 \pm 3.2$ to $10.0 \pm 2.8 ; P>0.05$ ) and they followed a frend similar to the Si groups in regard to the parturition time (fig. 3). 


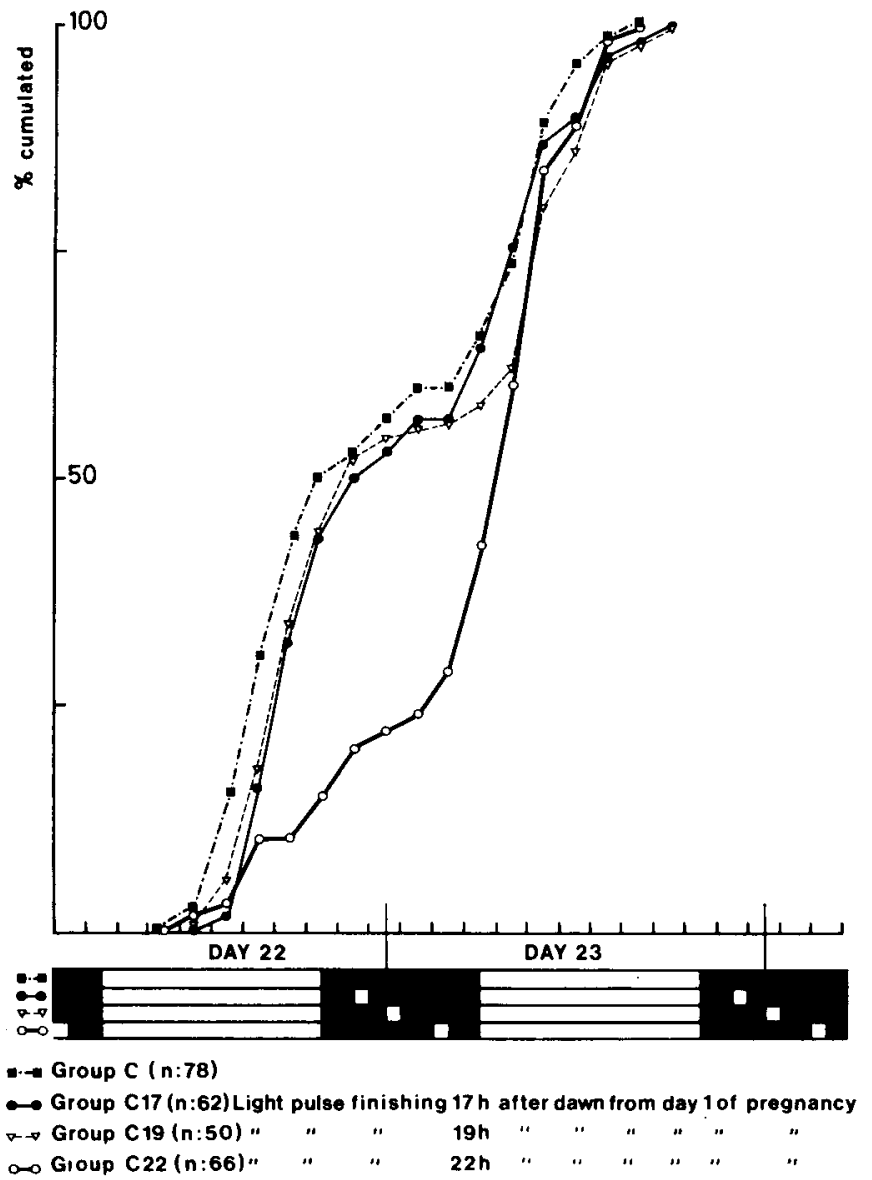

FIG. 4. - Parturition distributions in rats submitted to a control light regime (14L-10D) according to the time of a 1-hr light pulse during the night and throughout pregnancy. Results observed under the main light regime and without an additional pulse (group C) are also shown.

\section{Experiment II.}

In order to study the effect of a reduction in the total number of light pulses, a group of rats (group S19-6d) was submitted, during the last 5 to 6 days of pregnancy, to the same light pulse which had retarded the parturition time when given throughout pregnancy (group S19). The results for these two groups are presented in figure 5. They were compared to a pool of the groups in which the parturition time was not modified by a light pulse. The results obtained with the basic regime are also shown in figure 5. The parturitions of group S19-6d were distributed as those of group S19 $(P>0.05)$ and groups $S 20$ and $S 21(P>0.05)$; statistical analysis showed that it was different $(P<0.01)$ from the pool of groups $S 10$ to $\$ 17$ and group $S 23$ which was considered as a control. The stillbirth rates and the litter size were similar $(P>0.05)$ in groups S19-6d, S19, S20 and S21. 


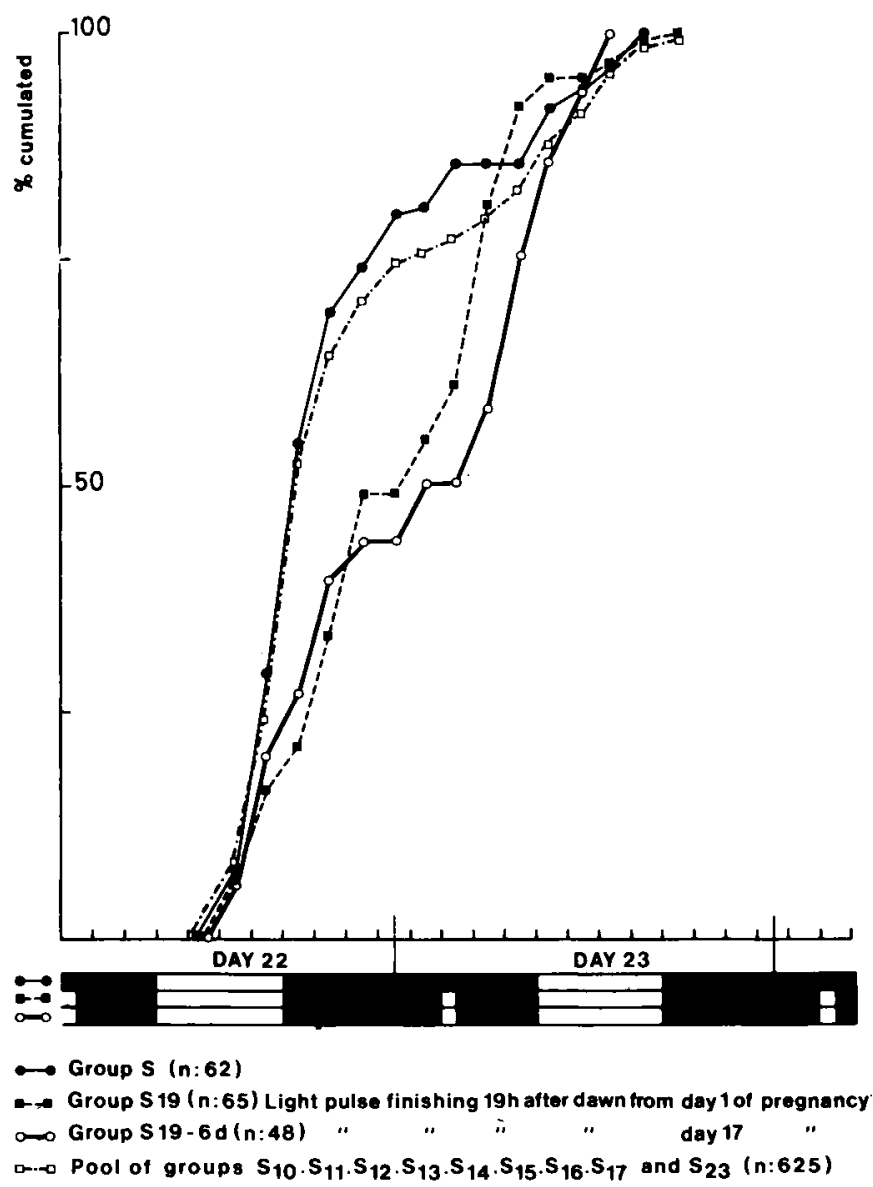

FIG. 5. - Parturition distribution in rats submitted to a light pulse ending 19 hrs ofter « dawn » throughout pregnancy (group S19) or during the final days (group S19-6d) under a short-light regime (8L-16D). The pool of the groups in which a light pulse during the night has no effect under this light regime is considered as the control. Results observed under the main light regime and without an additional pulse (group S) are also shown.

In group S12-17, a 5-hr light pulse was used. The light stimulation, however, occurred at a time which did not coincide with the photoinductible phase observed previously. The results are presented on figure 6 . They were compared to the pooled results obtained from the groups submitted to a 1-hr light pulse given in the same period of the dark phase (groups S13, S14, S15, S16 and S17). The two curves plotted from the results had the same shape but statistical analysis showed them to be divergent $(P<0.01)$; the $2-h r$ phase difference observed between them was probably responsible for that variance. The stillbirth rate of group S12-17 was less than the mean of groups $\mathrm{S} 13, \mathrm{~S} 14, \ldots ., \mathrm{S} 17(2.8$ vs $5.8 \mathrm{P} .100 ; 0.01<\mathrm{P}<0.05)$ but their prolificies did not differ $(P>0.05)$. 


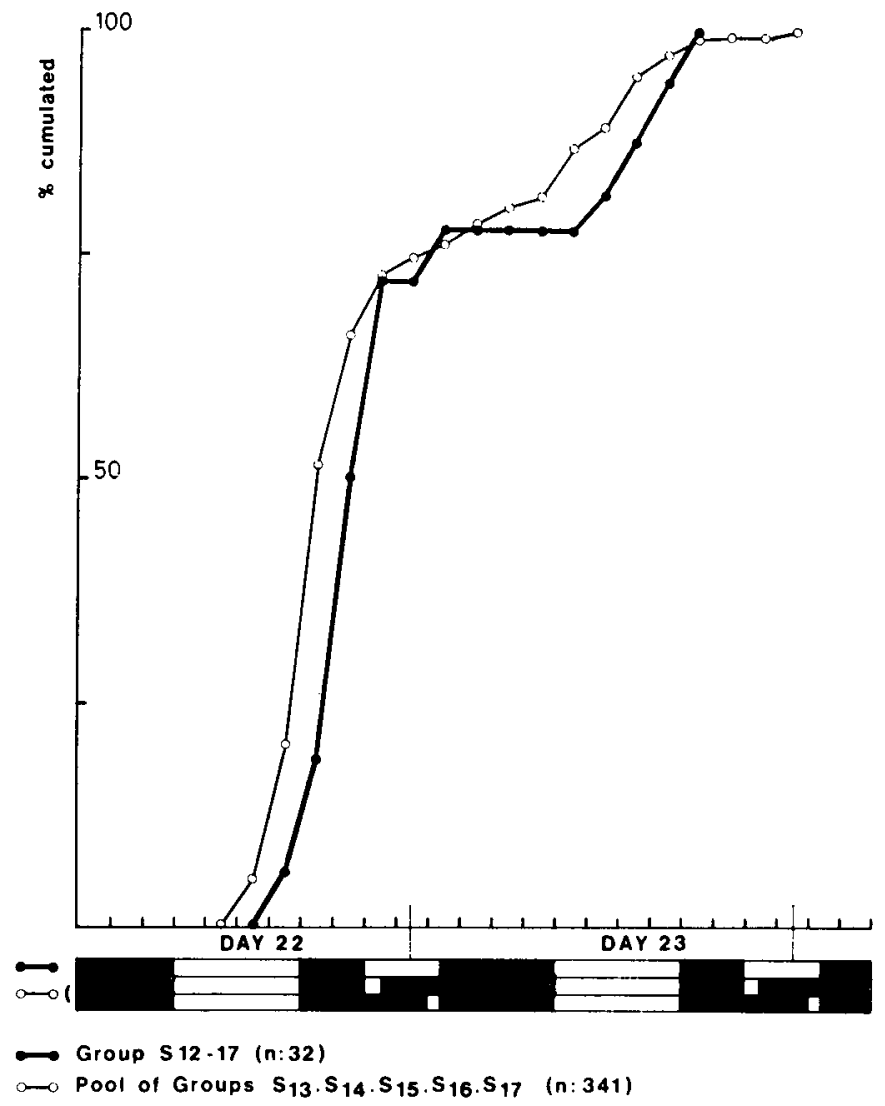

FIG. 6. - Parturition distributions in rats submifted to a short-light regime (8L-16D) and to a long light pulse given outside the photoinducible phase (group S12-17). The pool of the in which a 1-hr light pulse has been used during the same period of the night is considered as the control.

\section{Discussion.}

The first experiment demonstrates that the rat has a photoinducible phase comparable to that found in other biological systems : insects (Pittendrigh and Minis, 1964), birds (Follett, 1973 ; Lofts and Lam, 1973 ; Farner, 1975) ; hamsters (Menaker and Eskin, 1967 ; Elliott, 1976) and sheep (Ravault and Ortavant, 1977 ; Garnier et al., 1977). The stimulation of that phase by an appropriate light schedule leads to a delay of a proportion of deliveries under both the light regimes studied. The apparent inhibitory effect of the stimulation cannot be explained because the intervening physiological processes, regulated by light, are not yet known. However, these results agree with previous work by Bosc and Nicolle (1980) : the longer the daily photoperiod, the longer the length of pregnancy. It is noteworthy that, after stimulation of the photoinducible phase, the parturitions are distributed as observed previously under a long-light regime in which the final hours of the daily light exposure 
coindide with the period of the inducible phase observed with a short-light regime. Our results also support those of Chen and Besch (1975) who noted an extended pregnancy with a skeleton regime of $2 L-2 D$ as compared with the control regime of $12 \mathrm{~L}-12 \mathrm{D}$.

When a constant light-dark cycle is applied throughout pregnancy, the photoinducible phase occurs at the end of the night. Thus, under the two basic light regimes used in experiment I, a light pulse ending 22 hrs after dawn delayed most of the parturitions till day 23 of pregnancy (groups S22 and C22 ; figs. 2 and 4). However, the length of the phase seemed to depend on the main light regime. Under the present conditions using the short regime (8L-16D), that photoinducible phase laster over 3 to $4 \mathrm{hrs}$ and began $18 \mathrm{hrs}$ after « dawn ». With the control regime (14L-10D), the phase seemed shorter since, unlike a light pulse ending 22 hrs afters «lights on », a pulse finishing 19 hrs after dawn (group C19 vs group C22 ; fig. 4) did not modify the time of birth.

Experiment II shows that light modulates the duration of pregnancy by acting on the hormonal events initiating labor rather than by modifying the time of implantation. This is suggested by group S19-6d results showing that the stimulation of the photoinducible phase during the last days of pregnancy only had the same effect as stimulation throughout pregnancy (group S19) (fig. 5).

The second experiment also shows that considerably increasing the hours of light given outside the main photoperiod, and not coinciding with the photoinducible phase, did not affect the birth rhythm normally observed with the main period alone. This is suggested by the results for group S12-17 in which the animals received a total of $13 \mathrm{hrs}$ of light daily in two separate periods $(8 \mathrm{~h}+5 \mathrm{~h})$. Under those conditions, the total illumination was comparable to that of the control regime (14L-10D) described elsewhere by Bosc and Nicolle (1980). With 13 hrs of discontinuous light, most of the deliveries occurred on day 22 of pregnancy (group S12-17), whereas with $14 \mathrm{hrs}$ of continuous light, the births extended over two main periods : one on day 22 and the other on day 23 of pregnancy.

This would seem to indicate that the influences of the main photoperiod and of the photoinducible phase can be dissociated, even if they may be complementary in regulating the endogenous events leading to parturition.

Our experiments show that parturition time in the rat is photosensitive and that a photoinducible phase exists (according to the model of Bünning, 1960) whose duration and time of occurrence depend on the main light-dark cycle.

Reçu en août 1979.

Accepté en décembre 1979.

Acknowledgements. - The authors are indebted to Mr. A. Beguey and his team for animal care and to their colleagues who participated in monitoring the animals. Thanks are also due to Drs. Ph. Durand and R. Ortavant for their suggestions and comments and to Dr J. Williams for the final presentation of this manuscript.

Résumé. Le moment de la naissance a été utilisé pour rechercher l'existence d'une phase photosensible au cours du cycle diurne chez le Rat. Pour cela, une stimulation lumineuse d'une heure a été appliquée pendant la phase obscure à un moment déterminé par 
rapport au début de la photopériode principale ou aube conventionnelle. Les rates placées dès la saillie (jour 1 de la gestation) sous $8 \mathrm{~h}$ de lumière et $16 \mathrm{~h}$ d'obscurité, mettent bas en majorité l'après-midi du $22^{\mathrm{e}}$ jour de la gestation lorsque la stimulation lumineuse est faite entre la $9 \mathrm{e}$ ef la $18^{\mathrm{e}} \mathrm{h}$ ou entre la $22^{\mathrm{e}}$ et la $23^{\mathrm{e}} \mathrm{h}$ après l'aube ; ces parturitions sont reportées au $23^{\mathrm{e}}$ jour lorsque la stimulation est faite entre la $18^{\mathrm{e}}$ et la $22^{\mathrm{e}} \mathrm{h}$. De la même manière, avec $16 \mathrm{~h}$ de lumière et $8 \mathrm{~h}$ d'obscurité ef une stimulation finissant $22 \mathrm{~h}$ après l'aube, la plupart des mises-bas se produisent le $23 \mathrm{e}$ jour de la gestation ; avec une stimulation finissant 17 ou $19 \mathrm{~h}$ après l'aube, ces parturitions se répartissent en deux périodes préférentielles, l'une le $22^{\mathrm{e}}$ jour de la gestation (environ 50 p. 100 des mises-bas), l'autre le $23^{\mathrm{e}}$ jour. Pour les deux photopériodes étudiées, il existe en fin de phase obscure une phase photosensible dont la stimulation entraîne un report des mises-bas le $23 \mathrm{e}$ jour de la gestation. Ce report est aussi observé lorsque cette stimulation est limitée aux derniers jours de la gestation sous une photopériode $8 \mathrm{~h}$.

Par ailleurs, la plupart des mises-bas se produisent le $22^{\mathrm{e}}$ jour de la gestation sous une photopériode principale de $8 \mathrm{~h}$ à laquelle $5 \mathrm{~h}$ d'éclairement ont été ajoutées pendant la phase obscure et en dehors de la phase photosensible. Ceci suggère que l'effet du régime lumineux principal et celui qui résulte de la stimulation de la phase photosensible peuvent être dissociés.

\section{Références}

BOSC M. J.. NICOLLE A., 1980. Influence of photoperiod on the time of parturition in the rat. I. Effect of the length of the daily illumination in normal or adrenalectomized animals. Reprod. Nutr. Dévelop., 20, 735-745.

BUNNING E., 1960. Circadian rhythms and time-measurement in photoperiodism. In Biological clocks. Cold Spring Harb. Symp. Quant Biol., 25, 249-257.

CHEN C. L., BESCH E. L., 1975. Effect of altered photoperiod on estrous cycle, pregnancy and onset of puberty in the rat. Biol. Reprod., 12, 396-399.

ELLIOTT J. A., 1976. Circadian rhythms and photoperiodic time measurement in mammals. Fed. Proceed., 35, 2339-2346.

FARNER D. S., 1975. Photoperiodic controls in the secretion of gonadotropins in birds. Am. Zool., 15 (Suppl. 1), 117-135.

FOLLETT B. K., 1973. Circadian rhythms and photoperiodic time measurement in birds. J. Reprod. Fert., Suppl. 19, 5-18.

GARNIER D. H., ORTAVANT R., MANSARD F. X., TERQUI M., 1977. Influence de la lumière sur les variations de la testostérone chez le Bélier : mise en évidence d'une phase photosensible au cours du rythme diurne. C. R. Acad. Sci. Paris, Série D, 284, 61-64.

LOFTS B., LAM W. L., 1973. Circadian regulation of gonadotrophin secretion. J. Reprod. Fert., Suppl. 19, 19-34.

MENAKER M., ESKIN A., 1967. Circadian clock in photoperiodic time measurement : A test of the Bünning hypothesis. Science, 157, 1182-1185.

MITCHELL J. A., YOCHIM J. M., 1970. Influence of environmental lighting on duration of pregnancy in the rat. Endocrinology, 87, 472-480.

PLAUT S. M., GROTA L. J., ADER R., GRAHAM C. W., 1970. Effects of handling and the light dark cycle on time of parturition in the rat. Lab. Anim. Care, 20, 447-453.

PITTENDRIGH C. S., MINIS D. H., 1964. The entrainment of circadian oscillations by light and their role as photoperiodic clocks. Amer. Nafuralist, 98, 261-294.

RAVAULT J. P., ORTAVANT R., 1977. Light control of prolactin secretion in sheep. Evidence for à photoinducible phase during a diurnal rhythm. Ann. Biol. anim. Bioch. Biophys., 17, 459-473.

SIEGEL S., 1956. Non parametric statistics for the behavioral sciences. Int. Student ed., McGraw-Hill Bock Co. Inc, Kogakusha Co. Ltd.

SNEDECOR G. W., COCHRAN W. G., 1957. Statistical methods, 6th ed. The lowa State Univ. Press, Ames USA. 